\title{
SBUs: Hot, New Topic in the Management of Diversification
}

\author{
Diversified firms suffering from profitless growth are moving \\ away from traditional planning and adopting the strategic \\ business unit approach to overall corporate strategy.
}

WILLIAM K. HALL

William K. Hall teaches business policy in the Graduate School of Business at the University of Michigan.

It started in 1971 in the executive offices at General Electric, the world's most diversified company. Corporate management at GE had been plagued during the 1960s with massive sales growth, but little profit growth. Using 1962 as an index of 100 , dollar sales grew to 180 by 1970 ; however, carnings per share fluctuated without growth between 80 and 140 , while return on assets fell from 100 to 60. Thus, in 1971, GE executives were determined to supplement GE's vaunted system of management decentralization with a new, comprehensive system for corporate planning.

The resulting system was based upon the new concept of strategic business unitsSBUs, as they are now commonly called. Not only did this new system change the direction of planning at GE; it subsequently affected the corporate strategies and the planning processes in hundreds of other diversified firms around the world as well.

The SBU concept of planning is an intuitively obvious one, based on the following principles:

The diversified firm should be managed as a "portfolio" of businesses, with each business unit serving a clearly defined product-market segment with a clearly defined strategy.

\begin{abstract}
Each business unit in the portfolio should develop a strategy tailored to its capabilities and competitive needs, but consistent with the overall corporate capabilities and needs.

The total portfolio of business should be managed by allocating capital and managerial resources to serve the interests of the firm as a whole-to achieve balanced growth in sales, earnings, and asset mix at an acceptable and controlled level of risk. In essence, the portfolio should be designed and managed to achieve an overall corporate strategy.
\end{abstract}

As might be expected, the successful implementation of this intuitive approach provides a number of complex management choices and challenges. As a result, a heightened understanding of the benefits and costs of the SBU approach to the management of diversification is essential to the practice of general management. The objective of this article is to add to this understanding by summarizing the principles behind the SBU approach, and by examining the alternatives, benefits, and problems encountered to date in its successful implementation.

\section{A LOOK AT TRADITIONAL PLANNING}

In order to put the $\mathrm{SBC}$ concept of planning into a proper context, it is necessary to review briefly the traditional planning and resource allocation processes in large, diversified firms. 
These traditional processes grew out of the massive movement toward divisionalization and decentralization during the period 1920-1965. This movement began as a response to growth, diversity, and overall complexity in the large, diversified firm. In essence, the movement was essential, as one general manager put it, "to tailor responsibilities down to the size where a general manager could get his arms around them."

As the decentralized, divisionalized structure matured in the $1960 \mathrm{~s}$, formal planning became a way of life in the well-managed, diversified firm. Typically, the approach was initiated with the delineation of overall corporate mission, objectives, targets, and environmental assumptions. These were disseminated annually to the various divisions, where plans, projections, and sub-unit targets were developed as a response to these guidelines. Then a delicate, iterative process of "bottom up-top down" negotiation and consensus-seeking eventually resulted in an "approved plan" for

This approach to formal planning had a number of advantages:

It forced divisional managers to be explicit in their target-setting and goal-seeking, often on a profit center or investment center basis.

It allowed the corporate entity to add up the divisional pieces in advance, adjusting resource allocations and pushing divisions toward different targets when discrepancies against corporate objectives arose.

It allowed the development of sophisticated control systems to project, measure, and interpret deviations from the planned divisional results.

At the same time, however, this approach to planning and control was not without deficiencies. Divisional plans were frequently either overly optimistic or overly pessimistic. Depending upon the corporate "culture," they typically were based on one of three scenarios: extrapolated results, a philosophy that "next year things will get better," or a philosophy that "it's better to plan things a little conservatively so that we come out looking good at the end." Often, management commitment to plans was incomplete-either at the corporate or divisional level. Variances were frequently explained by unforeseen ex-

ternal factors, inadequate divisional resources, or deficiencies in the target-setting process itself. The total corporate plan, formed by adding up the divisional plans, often left corporate management without a clear grasp of either divisional or corporate strategy. Moreover, division plans were frequently approved (or rejected) without an explicit understanding of the strategy behind the plans or the risks and opportunities associated with this strategy. As one divisional general manager commented, "Planning without an understanding of corporate strategy was a lot like throwing darts in a darkened room."

In short, the traditional corporate plan almost always contained notebooks full of facts, figures, and forecasts, but it frequently failed to digest these in a way that provided key insights into stratcgics and business success factors at both the divisional and the corporate levels. The result, for many firms, was a decade of "profitless growth."

\section{THE SBU ALTERNATIVE}

In an attempt to deal with inadequacies in its traditional planning process, General Electric, guided by a task force of senior general managers and assisted by a team of management consultants, developed the SBU alternative to corporate planning. This process, now applied under a variety of names and in a varicty of ways in other diversified firms, is almost always based on four steps:

identification of strategic business elements, or units

strategic analysis of these units to ascertain their competitive position and long-term product-market attractiveness

strategic management of these units, given their overall positioning

strategic follow-up and reappraisal of SBU and corporate performance

\section{Identifying SBUs}

The fundamental concept in the identification of SBUs is to identify the discrete, indepen- 
dent product-market segments served by the firm. In essence, the idea is to decentralize on the basis of strategic elements, not on the basis of size or span of control. This can be accomplished, as one general manager observed, by "identifying natural business units which correspond to the degrees of freedom a manager has available to compete."

Thus, within GE, nine groups and fortyeight divisions were reorganized into fortythree strategic business units, many of which crossed traditional group, divisional, and profit center lines. For example, in three separate divisions, food preparation appliances were merged as a single SBU serving the "housewares" market. A very small part of the Industrial Components Division was broken out as a separate SBU, serving a distinct industrial product-market niche in the machine tool industry. Within Union Carbide, another firm adopting the SBU approach, fifteen groups and divisions were decomposed into 150 "strategic planning units," and these were then recombined into nine new "aggregate planning units."

Ideally, an SBU should have primary responsibility and authority for managing its basic business functions: engineering, manufacturing, marketing, and distribution. In practice, however, traditions, shared facilities and distribution channels, manpower constraints, and business judgments have resulted in significant deviations from this concept of autonomy. In General Foods, for instance, strategic business units were originally defined on a product line basis, even though several products served overlapping markets and were produced in shared facilities. Later, these product-oriented SBUs werc redefined into menu segments, with SBUs like breakfast food, beverage, main meal, dessert, and pet foods targeted toward specific markets, even though these, too, shared common manufacturing and distribution resources.

The General Foods example, and examples from many other firms adopting the SBU concept, point out that identification and definition are ultimately managerial decisions reflecting philosophical and pragmatic resolutions of the question: "What are our businesses and what do we want them to be?" As one general manager succinctly put it, "In our company an SBU ultimately becomes whatever subdivision corporate management wants it to be."

\section{Strategic Positioning}

The subsequent process of positioning an SBU is typically driven by two criteria: long-term attractiveness of the product-market segment served by the SBU, and the SBU's competitive position (business strength) within that product-market segment. A conceptual 2 X 2 matrix illustrating this positioning is shown in the following figure:

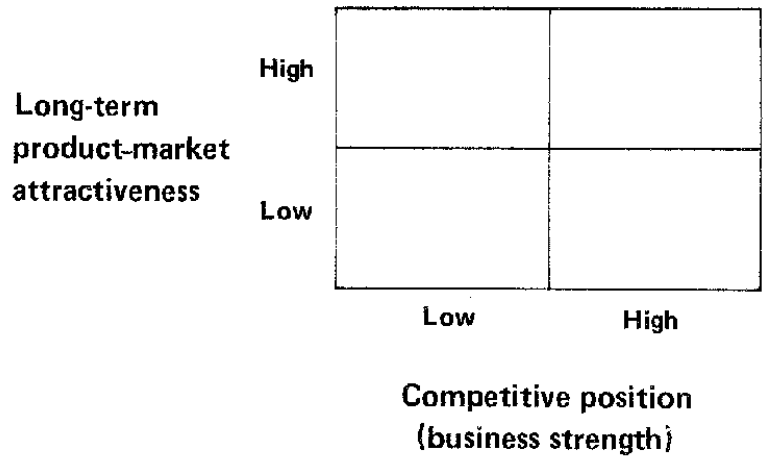

Here again, the scales of measurement and the precision of measurement along both scales vary significantly in practice. Since the choice of a measurement scale is more important then the degree of detail in measurement along the chosen scale, it will be discussed in some detail. ${ }^{1}$

Long-Term Product-Market Attractiveness. Two distinctive philosophies have evolved in ranking SBUs on this dimension. The first uses a single measure, almost always defined as the long-term projected real growth rate of the product-market segment. ${ }^{2}$ (The

1. I have secn primarily $2 \times 2$ matrices, although $3 \times 3$ and $4 \times 4$ matrices are used in some organizations.

2. In a few cases, I have also seen projected long-term return on assets used as a measure of segment attractiveness. 
split between high and low growth rates is sometimes arbitrarily set at 10 percent; other times it is set at the level of growth of the economy as a whole or at the level of growth of some sector of the economy.) Support for the growth rate definition of product-market attractiveness is clearly based upon a life cycle theory. With such a theory, attractive product-market segments are those in the development or "take-off" stage, and less attractive segments are in maturity or decline. Ideally, the long-term growth rate measures life cycle position and, hence, long-term productmarket attractivencss.

The second methodology for assessing product-market attractiveness uses a set of measures, some qualitative and others quantitative. There, the choice of measures and the actual assessment of SBU position against these measures can be made at the SBU level, the corporate level, or jointly. In corporate practice, I have seen all of these possibilities being utilized. At General Electric, for example, SBU product-market attractiveness is determined by examining and projecting ten criteria: segment size, segment growth rate (units and real dollars), competitive diversity, competitive structure, segment profitability, and technological, social, environmental, legal, and human impacts.

Competitive Position (Business Strength). As in the case of assessing long-term attractiveness, two alternative philosophies have evolved for ranking competitive position. Here again, the first is based on a single measure, generally defined as segment share or as segment share relative to competition. ${ }^{3}$ Support for this single factor concept comes from the thcory of experience curves, an approach to strategy formulation developed by the Boston Consulting Group. ${ }^{4}$

This theory suggests that the unit costs of

3. Rclative share is defined as the ratio of the SBU's dollar sales in the product-market segment to the dollar sales of the SBU's major competitor (or in some cases, competitors).

4. Sec, for example, the article by Hedley, "A Fundamental Approach to Strategy Devclopment," Long Range Planning (Dccember 1976), pp. 2-11. production, marketing, and distribution drop proportionately (in real terms) each time total output (experience) doubles. This decrease in unit costs presumably comes from learning effects, scale effects, substitution of lower cost factor inputs, redesign, and technology. Thus, if one believes that costs in an SBU are on an experience curve, it follows that there should be strong relationships between high market share (experience), lower costs, and higher profitability. ${ }^{5}$ In essence, high market share (or relative market share) becomes a surrogate measure of business strength relative to competition within the product-market segment.

In many firms, however, the marketshare-experience-curve approach to assessing competitive position is viewed as overly simplistic or even erroneous. In this regard, a number of arguments have emerged:

The competition with the most experience may be the "oldest" competitor. If this older firm has dedicated plant and equipment, it may not be able to exploit new, cost-reducing technology as rapidly as an emerging competitor.

Shared experience obtained from other related product-market segments may be as important as accumulated output in lowering costs. (That is, experience cannot be measured independently for each product-market segment).

External factors, technology breakthroughs, and other events may be as important as accumulated output in lowering (or in raising) costs.

In those firms that have either partially or totally rejected the experience-curve rationale, multiple measures of business strength have emerged. These measures are generally a mixture of qualitative and quantitative factors, and, depending upon the company, they can be defined and assessed either at the corporate or at the SBU level. At General Electric, for example, competitive position is evaluated on the following dimensions: segment size and SBU growth rate, share, profitability, margins, technology position, skill or weaknesses, image, environmental impact, and management.

5. See Buzzell, "Markct Share: Key to Profitability," Harvard Business Review (January-February 1975), for an empirical study lending some support to this hypothesis. 
Strategic handling. The strategic plan for an SBU is ultimately derived from its position with respect to long-term attractiveness (potential) and competitive position. Four combinations are possible.

Low potential/low position. An SBU in this category is clearly an unattractive member of the firm's portfolio for both the short run and long run. Furthermore, an infusion of resources to improve position will still leave the SBU in a low-potential segment. In essence, the SBU in this category is unworthy of major future commitments.

In the evolving jargon of the field, this "low/low" SBU is typically given the title of "cash trap," "mortgage," or "dog." Regardless of the title, the recommended strategic handling is always the same-manage the SBU to maximize short-term cash flow. In some cases this strategy can be accomplished through closing the SBU down or through rapid divestiture. In other cases, it can be handled by "harvesting" cash from the operation through ruthless cost cutting, short-term pricing policies, and sometimes through giving up market share and growth opportunities that absorb short-term cash.

Low potential/high position. Here an $\mathrm{SBU}$ is serving an unattractive product-market segment from a position of strength. Typically called a "bond" or "cash cow" in SBU parlance, the recommended strategic handling is to "milk" the entity for cash, although without the aggressiveness with which one would handle a "dog." The idea of selective cash "milking" is to preserve market position while generating dollars in an efficient fashion to support other, growth-targeted elements of the portfolio. Carefully targeted growth segments, stabilized pricing, differentiated products, selective cost reduction, less creative marketing, and selective capital investment are all means of achieving this goal.

High potential/low position. SBU elements in this category are typically termed "question marks," "problem children," or "sweepstakes" competitors. These elements are in an awkward position, for if they do not strengthen their competitive position, someone will almost certainly attack their product-market segment aggressively. Yet, the costs of strengthening their competitive position may not warrant the effort.

Thus, these elements are in a "get up or get out" strategic handling situation. Rigorous planning alternatives must be generated, cvaluated, and costed. And then, the SBUs in this category must be moved, either upward or out of the firm's portfolio through divestiture or consolidation.

High potential/high posilion. SBUs in this category would secm to have the best classification. As "stars" or "savings accounts," these represent the businesses that must be groomed for the long run. As such, they should be given the resources and corporate support to grow faster than the market segment in sales, profits, and cash flow.

The recommended strategic handling of portfolio SBU elements can be summarized as follows:

Dogs and cash cows are managed for short-term cash flow. Over the long run, dogs are divested or eliminated, while cash cows ultimately become dogs as their competitive position declines.

Question marks must either get into the star category or get out of the portfolio. In the first case, they should make the move with carefully developed strategic plans so that major risk elements are identified and contained.

Stars are short-run cash consumers and are managed for long-term position. Over the long run, as their segment attractiveness ultimately declines, they will become cash cows, generating cash to support the next round of stars.

\section{Strategic Follow-up and Reappraisal}

In most explanations of the SBU process, the typical discussion stops after an explanation of SBU identification, classification, and handling. Unfortunately, failure by corporations to exploit the last element-follow-up and reappraisal-has probably resulted in most of the frustrations and failures encountered 
with the SBU process to date. To be successful, the SBU process must be iterative and ongoing, incorporating strategic planning and reappraisal, as well as managerial control.

Strategic Planning. Simply saying that a business is a star or cash cow will not make anything happen. Once a decision on strategic handling has been reached in this regard, detailed strategic goals and action plans must be evaluated and implemented. Such planning clearly offers alternatives; as one manager put it, "Some companies forget that there's more than one kind of cow." Detailed analysis and conceptual thinking are both required here, focusing on key success factors and major risk elements apt to be encountered along the way.

Strategic Reappraisal. A one-time cvaluation and strategic positioning are also insufficient. In most companies in which SBUs are successful, strategic reappraisal is routinely conducted on an annual or biannual basis. In one large company, for instance, each SBU manager must completely reassess his competitive position and strategy in an annual presentation before corporate management. Simultaneously, a staff review group will present and evaluate alternatives to this positioning on a total portfolio basis.

In other organizations, such as GE, reappraisal is initiated when a strategic "trigger point"-an external factor projected to have a significant impact on SBU performanceoccurs. One GE manager described this system as follows: "For each business unit we require that management identify the sensitivity to these key external factors. These sensitivities must be identified in advance, and specific contingency plans must be ready in advance. Thus, we at least face the future with our eyes open!"

Managerial Control. Senior managers in many large firms also argue that the SBU approach to the management of diversification requires major changes in systems for budgeting, capital appropriation, measure- ment, reward, and managerial devclopment. One general manager described the problem in his firm as follows: "To me it makes little sense to go through a sophisticated SBU analysis and then continue to allocate capital simply on discounted rate of return. Moreover, it makes even less sense to continue to measure and reward SBU management on annual performance against a profit budget."

Very little information is available on the modifications in managerial control that accompany the SBU concept. ${ }^{6}$ However, General Electric has provided some interesting information on their systems in public sources.

SBU control systems with GE are based on key success indicators (called business screens). For each SBU, performance measurements are monitored on five broad criteria: market position, competitive position, profitability/cash flow, technological position, and external trigger points. Standards for each criteria are set and weighted differently, depending upon how the SBU is categorized. In addition, a "quality of performance" ranking is maintained as a measure of how well individual SBU managers have attained their standards of performance. As one GE manager put it, "the maturity of our SBU planning process could be measured when we began to bridge the gap between budgeting and the strategic plan."

The measurement and reward of managerial performance was perhaps the biggest shift in the revised GE system. Under the previous system of reward, GE had compensated key managers on the basis of residual earnings-controllable profits during the planning period less a charge for corporate services and capital. Under the SBU system, however, SBU managers in different sectors of the matrix are measured and compensated differentially according to a bonus schedule, as shown in the table.

$\begin{array}{ccc}\text { Current } & \text { Future } \\ \text { SBU } & \text { Performance } & \text { Performance } \\ \text { Classification (Residual Income) } & \text { (Strategy) } & \text { Factors }\end{array}$

$\begin{array}{clll}\text { Invest/Grow } & 40 \% & 48 \% & 12 \% \\ \text { Selectivity } & 60 & 28 & 12 \\ \text { Harvest/Divest } & 72 & 16 & 12\end{array}$

Clearly, SBU elements with an invest-andgrow classification are being rewarded on the basis of long-term (strategic) contributions.

6. Recently, Richard Bettis and I initiated a research project at the University of Michigan on these issues. 
While GE has recognized the difficulty of such a long-term appraisal, key managers in the company agree that an invest-and-grow manager can be cvaluated and rewarded on the quality of his long-run strategy through a careful appraisal of his manpower plans, facilities plans, action programs, and competitive evaluation. As one GE manager described the system, "Of course, it has measurement problems, but so do most good compensation systems. In the end, I'm convinced that our revised executive incentive compensation system is the key that will make the SBU process work."

Management development in GE has also shifted to reflect differential needs in differcntial business elements. Invest-and-grow business managers are developed to foster entrepreneurial characteristics. Cash cow (selectivity) business managers are developed to take sophisticated and hard looks at their businesses, and harvest and divest managers are developed with a heavy orientation toward experience, operations, and cost-cutting.

The philosophy behind the GE management systems is a classical one: Effective strategy implementation decisions will be made only if managerial selection, appraisal, and incentives are consistent with the strategy and with the planned results. As one manager in a large, diversified company recently observed, "Most firms have gone only half way with the SBU concept-they position their product-market segments and then go right on rcwarding and promoting managers on traditional criteria. In the end the companies which make the SBU concept work will be those which change all management systems; developing and rewarding SBU managers differentially depending upon their SBU position and the strategic handling which is appropriate for their element of the portfolio."

\section{PITFALLS IN SBU ANALYSIS}

\section{Failure To Go All the Way}

As discussed above, the failure to tie all management systems to the SBU approach is frequently a key pitfall in SBU analysis. In addition, there is the ever-present danger that short-term perturbations in the economy may drive invest-and-grow managers away from the long-term orientation required by the SBU approach. One senior manager commented on this problem as follows: "I'Te 1974-1975 recession came when many companies were moving onto the SBU system. Unfortunately, indiscriminate cost cutting and cash conservation caused many of these firms to cover their heads with a blanket, going back to the 'good old ways' of doing business. In the end, the good companies of the 1980 s will be those that stayed with their strategies during the recession-repositioning themselves in the short run to strengthen themselves for the long run."

\section{Doctrinaire Approaches}

There is a wide variety of alternatives for identifying product-market segments, for evaluating these segments, and for developing an SBUs strategy vis-à-vis competition. The application of a single methodology in a doctrinaire fashion is likcly to create dissension, confusion, and misleading results. $\mathrm{SBC}^{\top}$-based planning, even more than traditional corporate planning, must be conducted to generate "multibusiness insights"-that is, to learn more about one's businesses than the competitor knows about his. As one manager succinctly observed, "The real payback from SBU planning is an intangible one-it comes slowly as you develop a strategic understanding of your businesses and your portfolio."

\section{Transition Costs}

Both the measurable and the hard-to-measure costs of moving from the traditional corporate planning process to the portfolio planning process must also be considered. Managers who have risen through the ranks of a firm to positions of leadership in groups and 
divisions are not apt to "jump for joy" when they are reorganized and retitled "dogs," "cows," or "question marks." Moreover, their subordinates are apt to be even more unsure as they assess their future employment, career development, and promotion prospects. One middle manager in a business redefined as a cash cow commented on this problem:

I spent two years in an MBA program learning how to run a business as a profit/investment center. Now, suddenly I'm told to manage my department as a cash center.

Then the corporation turns down a major expansion proposal from our division, reallocating investment funds to another set of businesses. I don't understand it, I don't like it, and I really wonder what my future looks like with the XYZ company.

In addition to these costs of managerial adjustment, there is some question as to whether traditionally trained managers can manage cows or dogs at all. A related question is whether or not a firm can develop and keep the diversified managcrial talent necessary for managing diversified portfolio elements. And finally, "going all the way" with SBU implementation involves the high costs of adding new managerial systems or organization, planning, and control.

Transition costs can (and are) being handled in part by executive development programs within companies and within management education institutions. While these programs are useful-perhaps even essentialto a company shifting to the SBU philosophy, management transition takes time and involves some painful reallocations. It remains to be seen how much lime and pain will be incurred as organizations shift and how many of these organizations will be able to endure these transition costs. The kcy issue, as one middle manager put it, will be "to convince managers that there are other ways to heaven than a star."

\section{New Ventures and R\&D}

A fourth unresolved problem with the SBU approach to date involves corporate strategies toward new ventures and research and development--that is, toward the businesses of the future.

In theory, it would appear that R\&D in a cash cow should be climinated or restricted to short-term projects generating cost reductions. It is possible that a major R\&D effort in a cow could result in major new markets or products that could ultimately turn the cow into a star (or lengthen the life during which the cow continues to generate cash). However, failure to maintain a competitive advantage in R\&D within a cow could give competitors market leadership, accelerating, in effect, the cow's movement toward the dog category.

SBU theory would also seem to indicatc that new ventures, $\mathrm{R} \& \mathrm{D}$, and acquisitionmerger policies should be directed at potential stars. The question is, how does one identify future stars in business segments where the firm has little or no experience, and should one develop these business segments internally or through acquisition-merger?

Determining the role of new technology and searching for stars of the future that are outside of the firm's existing portfolio are difficult-in theory and in practice. In essence, while the SBU philosophy has provided now insights into the management of existing businesses, new concepts are needed for managing additions to the portfolio effectively.

\section{SBUs in Nondiversified Firms}

It is obvious that $\mathrm{SBU}$ analysis has evolved as a powerful concept in the management of diversification. Still, while diversification has been a major trend throughout world corporations for the past quarter-century, many large, nondiversilied businesses-even entire corporations-rcmain, in effect, single SBU's.

The question must be asked: Are there any concepts that would aid in strategy formulation within a nondiversified firm? Clearly there are some:

consideration of resegmenting the existing single product-market segment into new segments to gain 
improved competitive position and segment attractiveness

consideration of using cash flow from the existing single product-market segment to develop new starseither through acquisition or through internal development (that is, manage the base business as a cow to feed the stars of the future)

While these ideas have conceptual merit, they are not without problems. Resegmentation takes time, money, and managerial skill. Diversification does also, and diversification raises the additional question of direction. Unfortunatcly, it is uncommon for the nondiversified firm to possess simultaneously all three elements-time, money, and skill in shifting strategies. Fven when these three factors are present to some degree, reinvestment decisions in the base business tend to claim priorities on these scarce resources.

This strategic dilemma of the maturing, nondiversified firm is a major challenge to management and to society. While SBU analysis aids in understanding the dilemma, it has not as yet provided the conceptual framework to aid in the resolution.

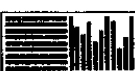

There is little question that formal SBU analysis-identification, positioning, handling, and follow-up-provides new insights into the management of diversilication. While the total number of diversified firms adopting some variant of this approach is unknown, one estimate is that 20 percent of the "Fortune 500" manufacturing firms are utilizing the concept. And while after only five years of experience it is too early to assess its impact, some testimonials provide a feel for preliminary management reaction:

General Electric: "GE is growing rapidly as a result of its strong financial controls and marketing strategies. ... Two basic failures-an absence of strategic planning and a dearth of financial controls have brought [their major domestic competition] to an [unfortunate] pass."7

Mead Paper: "Our track record for earnings won't validate it, but we will make this thing (SBU analysis) work. You can't help but improve a company if you

7. "The Opposites: GE Grows While Westinghouse Shrinks," Business Week (January 31, 1977), pp. 60-66. get rid of the losers and step up the winners. Our program is the common thread runing through the company."

Union Carbide: "Business strategies that reflect the category assigned to the business have been developed for each strategic planning unit. . . . At present, about 60 percent of Union Carbide's total sales is concentrated in businesses in growth categories. For the period 1975 to 1979 , about 80 percent of forecasted (capital) expenditures has becn allocated to these businesses."

Armco Steel: "We [now] know the businesses we should pursue aggressively, those to maintain at the current level, and those to deemphasize or phase out. We can set goals that are reasonable ... as they are attractive. And, importanily, we can have confidence in achieving our goals." 10

However, the concept of portfolio management, like any other concept, must continue to evolve and mature as a philosophy for the effective management of diversification. And this evolution must come to grips with a number of issues that still are not fully resolved: tailoring and restructuring planning and control systems, avoiding doctrinaire approaches, and effectively managing transition costs. In addition, the handling of research and development and new ventures, as well as the application of the SBU concept to the nondiversified firm, provide major challenges to both business and business research.

There is little question, however, that the SBU approach to the management of diversification will leave a major mark-just as the movement to divisionalization and decentralization did twenty-five years ago. As one senior executive put it, "SBU analysis makes planning discontinuous.... It forces general managers to develop competitive and multibusiness insights at a strategic level. ... And in the uncertain, rapidly changing world of the $1980 \mathrm{~s}$, this kind of strategic planning will become a way of life."

8. J. W. McSwiney, Chairman, in "Mead's Technique to Sort Out the Losers," Business Week (March 11, 1972), pp. 124-127. 6.

9. 1975 Annual Repart, Union Carbide Corporation, p.

10. C. W. Verity, Chairman, in "Why a Portfolio of Businesses?" Planning for Corporate Growth, Planning Executives Institute (December 1974), pp. 54-60. 